\title{
Air pollution and acute exacerbations of idiopathic pulmonary fibrosis: back to miasma?
}

\author{
Mark G. Jones ${ }^{1}$ and Luca Richeldi ${ }^{1,2}$
}

\begin{abstract}
Affiliations: 'Academic Unit of Clinical and Experimental Sciences, University of Southampton Faculty of Medicine, University Hospital Southampton, Southampton, ${ }^{2}$ Southampton NIHR Respiratory Biomedical Research Unit, University Hospital Southampton, Southampton, UK.
\end{abstract}

Correspondence: L. Richeldi, Level E, South Block, University Hospital Southampton, Southampton, S016 6YD, UK. E-mail: L.Richeldidsoton.ac.uk

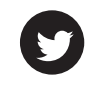

@ERSpublications

Air pollution might be the first modifiable risk factor for acute exacerbations of idiopathic pulmonary fibrosis http://ow.ly/rSpWb

Centuries ago miasma (from $\mu i \alpha \sigma \mu \alpha$, the ancient Greek word for pollution) was considered to be a poisonous vapour filled with particles from decomposed matter. The miasmatic theory held that diseases such as cholera or the Black Death were caused by a noxious form of "bad air", also known as "night air", emanating from rotting organic matter [1]. In those days, breathing was considered to be a dangerous, although unavoidable, exercise. The theory was accepted from ancient times in Europe, India and China, and was eventually displaced only in the 19th century by the discovery of germs. In 1876, Robert Koch proved that a bacterium had caused anthrax and this discovery brought a definitive end to miasmatic theory. Contagionism prevailed over miasmatism and, thereafter, air was not considered a cause of human disease. Instead, the concept of "fresh air" as a beneficial factor for human health became widely accepted, until recently. After World War II, air pollution became an increasingly recognised threat, initially as a consequence of radioactive fallout from atomic warfare and testing. Subsequently, a non-nuclear event, the Great Smog of 1952 in London, which killed at least 4000 people [2], prompted some of the first major modern environmental legislation, the Clean Air Act of 1956 [3]. Following this, air pollution began to draw major public attention worldwide. Recently, the European "Year of Air" initiative has again publicised that air pollution exposure is an important threat to public health. With formal classification of outdoor air pollution as a carcinogen and evidence of associations ranging from low birth weight to acute exacerbations of chronic lung diseases such as asthma and chronic obstructive pulmonary disease (COPD), it represents an obvious candidate as a risk factor or causative agent in the pathogenesis and/or the progression of every chronic respiratory disorder [4-11].

An acute worsening of respiratory symptoms is a well-recognised phenomenon in various chronic respiratory diseases including asthma, COPD and idiopathic pulmonary fibrosis (IPF). Historically, bacteria, viruses and environmental pollutants have been proposed as aetiological factors of such acute events or exacerbations; however, there is increasing recognition that their pathogenesis is complex and that triggering factors may be very heterogeneous [12-14]. In this context, one of the most enigmatic but clinically important events is an acute exacerbation of IPF. Epidemiological data from patients with IPF identify a 1 -year incidence of $14.2 \%$ and an acute exacerbation is a significant predictor of poor survival, with a 50\% in-hospital mortality rate [14]. In 2007, a consensus definition with strict clinical and radiographic criteria was proposed: an unexplained new or worsening shortness of breath within the past 30 days, new lung infiltrates demonstrated by chest high-resolution computed tomography, and exclusion

Received: Nov 212013 | Accepted: Nov 262013

Conflict of interest: Disclosures can be found alongside the online version of this article at www.erj.ersjournals.com

Copyright @ERS 2014 
of any reversible and recognisable aetiology causing lung injury are the three key elements to define an acute exacerbation of IPF [15]. Although this definition enabled acute exacerbations to become a key end-point in randomised clinical trials, the requirement to fulfil all diagnostic criteria has restricted general applicability in clinical practice and debate continues regarding the usability of this definition [16].

Even if acute exacerbations of IPF are not uncommon events for physicians taking care of such patients, their pathobiology is still poorly understood. It has been proposed that some of them may be triggered by unrecognised viral infection [17], acid microaspiration [18] or mechanical lung stress [19] (table 1). Gene array analysis of IPF lung tissue homogenates suggested that acute exacerbations are characterised by a pattern of enhanced epithelial injury and proliferation [20]. In addition, plasma biomarker analysis identified elevations in markers of type II alveolar epithelial cell injury and/or proliferation, endothelial cell injury, and coagulation [21]. However, it remains undetermined whether these acute events represent an acceleration of the primary disease process or are the consequence of as yet unrecognised second extrinsic trigger(s). Given these uncertainties, no preventative strategies have been identified and, although current guidelines suggest the use of high-dose corticosteroids [22], the efficacy of any pharmacological treatment remains unproven.

While there are epidemiological data correlating interstitial lung diseases with inhaled agents such as cigarette smoke, organic antigens and wood dusts [23], the relationship with air pollution is not known. In this issue of the European Respiratory Journal (ERJ), JOHANNSON et al. [24] report the first association between ambient air pollution exposure and risk of acute exacerbation of IPF. In a well-characterised, longitudinal Korean cohort of 436 patients with IPF, ambient air pollution exposure data for ozone $\left(\mathrm{O}_{3}\right)$, nitrogen dioxide $\left(\mathrm{NO}_{2}\right)$, particulate matter $<10 \mu \mathrm{m}$ in aerodynamic diameter $(\mathrm{PM} 10)$, sulfur dioxide $\left(\mathrm{SO}_{2}\right)$ and carbon monoxide (CO) was retrospectively obtained. Over a 10-year period, 75 patients experienced at least one acute exacerbation, with a resulting incidence rate of 5.2 exacerbations per 100 patient-years. Acute exacerbations were significantly associated with increases in mean level, maximum level and number of times of United States Environmental Protection Agency National Ambient Air Quality Standards were exceeded for $\mathrm{O}_{3}$ (hazard ratio (95\% CI) 1.57 (1.09-2.24), 1.42 (1.11-1.82), and 1.51 (1.17-1.94), respectively) and $\mathrm{NO}_{2}$ (hazard ratio (95\% CI) 1.41 (1.04-1.91), 1.27 (1.01-1.59), and 1.20 (1.10-1.31), respectively). No such association was identified with $\mathrm{SO}_{2}, \mathrm{PM} 10$ or CO.

These findings suggest that higher exposures to $\mathrm{O}_{3}$ and/or $\mathrm{NO}_{2}$ may cause acute exacerbations of IPF. Importantly, they are consistent with the data on the effect of air pollution on exacerbations in other chronic lung diseases [4-7]. No significant correlation between air pollution exposure and mortality was identified. Given the very poor prognosis of patients with acute exacerbations of IPF (illustrated in this study with a mortality rate of $67 \%$ at 6 months) such a relationship would be anticipated. Failure to identify one is likely to be a consequence of the lack of statistical power in the cohort studied. Nonetheless, this concept is supported by recent research identifying that air pollution exposure shortens the survival of patients diagnosed with lung cancer [25], and epidemiological analysis of the American Cancer Society Cancer Prevention Study II Cohort, which has identified a positive association of $\mathrm{O}_{3}$ and $\mathrm{NO}_{2}$ with mortality [26].

This retrospective study also has limitations. The analysis was based on regional air quality monitoring data; however, recent research has proposed the importance of advanced exposure modelling to enable accurate individualised air pollution exposure assessments [26]. No association with PM10 was identified. Unfortunately, smaller particulate matter such as PM2.5, which has greater penetration to the gas exchange region of the lung and has been strongly correlated with mortality [26], was not studied, raising the possibility that an association with particulate matter may have been missed. It is also unclear whether air pollution exposure alone could be the causative agent of an acute exacerbation. It may represent one of

\section{TABLE 1 Known or putative risk factors for an acute exacerbation of idiopathic pulmonary fibrosis}

Predisposing factors

Precipitant factors

\author{
Decreased forced vital capacity \\ Genetic factors \\ Never having smoked \\ Exposure to air pollution \\ Drugs \\ Gastro-oesophageal reflux/microaspiration \\ Mechanical lung stress/surgery \\ Viral infection
}


multiple potentially interacting extrinsic risk factors contributing to the pathogenesis of these events in predisposed individuals.

Even considering these limitations, to our knowledge, this study represents the first evidence of a potentially modifiable risk factor for acute exacerbations of IPF. While the association identified is modest, it is likely to be clinically meaningful. A multicentre, prospective study would be required to confirm these findings and their general applicability. At a minimum, to further increase our understanding of any relationship of air pollution with interstitial lung disease in disease pathogenesis and/or disease progression, it is essential that all epidemiological air pollution studies now consider interstitial lung diseases as an outcome measure.

These results also raise the possibility that air pollution is a confounder in clinical trials utilising acute exacerbations as a study end-point and emphasise the importance of effective randomisation to minimise unrecognised confounding effects. Air pollution is probably only one of the multiple, as yet unrecognised, potential confounding factors important in the pathogenesis and/or progression of IPF. Nonetheless, the possibility of including air pollution exposure data among routinely collected variables in clinical trials in IPF should be considered for future trials.

Finally, this study reinforces the importance of effective advocacy for large-scale reductions in air pollution exposure. Best practice for an individual patient with IPF should now include education regarding awareness and avoidance of excess ambient air pollution. Although this intervention currently has no direct supporting evidence, it would be easy to institute, is free, has no side-effects, and the results published in this issue of the ERJ support the concept that a reduction in air pollution exposure would reduce acute exacerbations and possibly mortality. With the increasing number of respiratory diseases for which morbidity and mortality have been correlated with air pollution exposure, we should now research the feasibility and the efficacy of air pollution education forming a routine part of the management of every patient with a chronic respiratory disease.

It seems that we must revisit the miasmatic theory, that breathing is dangerous and the final cause of many deadly diseases. However, today it is different: we should reflect on the fact that we are the ones responsible for the modern "bad air".

\section{References}

Last JM, ed. A Dictionary of Public Health. Oxford, Oxford University Press, 2007.

Ministry of Health. Mortality and morbidity during the London fog of December 1952 Reports on Public Health and Medical Subjects No 95. London, HMSO, 1954.

Clean Air Act 1956, 1956c.52. London, HMSO, 1956.

Andersen ZJ, Bønnelykke K, Hvidberg M, et al. Long-term exposure to air pollution and asthma hospitalisations in older adults: a cohort study. Thorax 2011; 67: 6-11.

Goss $\mathrm{CH}$, Newsom SA, Schildcrout JS, et al. Effect of ambient air pollution on pulmonary exacerbations and lung function in cystic fibrosis. Am J Respir Crit Care Med 2004; 169: 816-821.

6 Nawrot TS, Vos R, Jacobs L, et al. The impact of traffic air pollution on bronchiolitis obliterans syndrome and mortality after lung transplantation. Thorax 2011; 66: 748-754.

7 Gan WQ, FitzGerald JM, Carlsten C, et al. Associations of ambient air pollution with chronic obstructive pulmonary disease hospitalization and mortality. Am J Respir Crit Care Med 2013; 187: 721-727.

Brunekreef B, Annesi-Maesano I, Ayres JG, et al. Ten principles for clean air. Eur Respir J 2012; 39: 525-528. Brunekreef BB, Holgate STS. Air pollution and health. Lancet 2002; 360: 1233-1242.

10 Loomis D, Grosse Y, Lauby-Secretan B, et al. The carcinogenicity of outdoor air pollution. Lancet Oncol 2013; 14: 1262-1263.

11 Pedersen M, Giorgis-Allemand L, Bernard C, et al. Ambient air pollution and low birthweight: a European cohort study (ESCAPE). Lancet Respir Med 2013; 1: 695-704.

12 Jackson DJ, Sykes A, Mallia P, et al. Asthma exacerbations: origin, effect, and prevention. J Allergy Clin Immunol 2011; 128: 1165-1174.

13 Wedzicha JA, Decramer M, Seemungal TAR. The role of bronchodilator treatment in the prevention of exacerbations of COPD. Eur Respir J 2012; 40: 1545-1554.

14 Song JW, Hong SB, Lim CM, et al. Acute exacerbation of idiopathic pulmonary fibrosis: incidence, risk factors and outcome. Eur Respir J 2011; 37: 356-363.

15 Collard HR, Moore BB, Flaherty KR, et al. Acute exacerbations of idiopathic pulmonary fibrosis. Am J Respir Crit Care Med 2007; 176: 636-643.

16 Collard HR, Yow E, Richeldi L, et al. Suspected acute exacerbation of idiopathic pulmonary fibrosis as an outcome measure in clinical trials. Respir Res 2013; 14: 73.

17 Wootton SC, Kim DS, Kondoh Y, et al. Viral infection in acute exacerbation of idiopathic pulmonary fibrosis. Am J Respir Crit Care Med 2011; 183: 1698-1702.

18 Lee JS, Song JW, Wolters PJ, et al. Bronchoalveolar lavage pepsin in acute exacerbation of idiopathic pulmonary fibrosis. Eur Respir J 2012; 39: 352-358.

19 Kondoh Y, Taniguchi H, Kitaichi M, et al. Acute exacerbation of interstitial pneumonia following surgical lung biopsy. Respir Med 2006; 100: 1753-1759.

20 Konishi K, Gibson KF, Lindell KO, et al. Gene expression profiles of acute exacerbations of idiopathic pulmonary fibrosis. Am J Respir Crit Care Med 2009; 180: 167-175. 
21 Collard HR, Calfee CS, Wolters PJ, et al. Plasma biomarker profiles in acute exacerbation of idiopathic pulmonary fibrosis. Am J Physiol Lung Cell Mol Physiol 2010; 299: L3-L7.

22 Raghu G, Collard HR, Egan J, et al. An official ATS/ERS/JRS/ALAT statement: idiopathic pulmonary fibrosis: evidence-based guidelines for diagnosis and management. Am J Respir Crit Care Med 2011; 183: 788-824.

23 Taskar VS, Coultas DB. Is idiopathic pulmonary fibrosis an environmental disease? Proc Am Thorac Soc 2006; 3 : 293-298.

24 Johannson KA, Vittinghoff E, Lee K, et al. Acute exacerbation of idiopathic pulmonary fibrosis associated with air pollution exposure. Eur Respir J 2014; 43: 1124-1131.

$25 \mathrm{Xu}$ X, Ha S, Kan H, et al. Health effects of air pollution on length of respiratory cancer survival. BMC Public Health 2013; 13: 800 .

26 Jerrett M, Burnett RT, Beckerman BS, et al. Spatial analysis of air pollution and mortality in California. Am J Respir Crit Care Med 2013; 188: 593-599. 